Referencia para citar este artículo: Saban-Ayala, K., \& Alarcón-Espinoza, M. (2018). Significados del actuar delictivo adolescente: perspectiva de sus madres. Revista Latinoamericana de Ciencias Sociales, Niñez y Juventud, 16(2), 929-942. doi:https://doi.org/10.11600/1692715x.16219

\title{
Significados del actuar delictivo adolescente: perspectiva de sus madres*
}

\author{
KARLA $\boldsymbol{S}_{A B A N-A Y A L A}^{* *}$ \\ Investigadora Universidad de La Frontera, Chile. \\ MARINA ALARCÓN-ESPINOZA *** \\ Investigadora Universidad de La Frontera, Chile.
}

Artículo recibido en octubre 12 de 2017; artículo aceptado en enero 26 de 2018 (Eds.)

- Resumen (analítico): con el objetivo caracterizar los significados respecto al actuar delictivo que poseen las madres de jóvenes infractores de ley privados de libertad en un Centro de Régimen Cerrado en Chile, se realizó una investigación cualitativa de tipo descriptivo, mediante un muestreo de casos críticos, con una muestra de cinco participantes. La técnica de recolección de información fue la entrevista semi-estructurada y el análisis e interpretación de los datos obtenidos se realizó a través del análisis fenomenológico interpretativo (IPA). Los resultados dieron cuenta de cinco temas: atribución del origen de la conducta delictiva; consecuencias de la privación de libertad; factores que ayudan a que los jóvenes cambien su conducta; la revelación del actuar delictivo y dinámica familiar. Se discuten las implicanciones para procesos de intervención.

Palabras clave: desarrollo adolescente, delincuencia juvenil, relaciones familiares, patrones trasgeneracionales, terapia familiar (PsycInfo-APA).

\section{Meanings of teen crime actions: The perspectives of their mothers}

- Abstract (analytical): With the objective of characterizing the meanings of criminal acts that the mothers of young people who are serving sentences in a Youth Detention Centre, a descriptive qualitative study was carried out that selected a sample of five participants who are classified as critical cases. The study used the data collection technique of a semi-structured interview and Interpretive Phenomenological Analysis (IPA) was used to analyze and interpret the data that was obtained. The results identified five common themes among the mothers that were interviewed: attribution of origin of criminal conduct; consequences of the deprivation of liberty; factors that help young people change their behavior; the revelation of criminal acts; and family dynamics. The implications for intervention processes are discussed.

Este artículo de investigación científica y tecnológica presenta resultados de la investigación llevada a cabo para acceder al grado de Magíster en Terapia Familiar de la Universidad de La Frontera, Temuco, Chile, entre julio de 2013 y enero de 2015. Dicho informe se relacionó con la investigación denominada «Estrategia ecosistémica especializada de intervención diferenciada para favorecer la integración psicosocial de adolescentes infractores de ley» realizada entre el 30 de abril de 2012 y el 30 de julio de 2013, proyecto Fondef D08I-1205. Financiamiento: Conicyt, XVI Concurso Nacional de proyectos Fondef. Área: Otras Ciencias Sociales; subárea: interdisciplinaria.

** Magíster en Terapia Familiar, Universidad de La Frontera. Diplomado en Herramientas Clínicas para la intervención con adolescentes infractores de ley, Universidad de Chile. Psicóloga, Universidad Andrés Bello. Orcid: 0000-0002-2835-8755. Correo electrónico: k.ayala.saban@gmail.com

*** Magíster en Desarrollo Humano a escala Local y Regional, Universidad de La Frontera. Terapeuta Familiar, Instituto Chileno de Terapia Familiar. Doctoranda Programa de Doctorado Conjunto Universidad de Barcelona-Universidad Autónoma de Barcelona en Psicología de la Comunicación y Cambio. Académica e Investigadora Universidad de La Frontera, Chile. Orcid: 0000-0002-6636-083X. Índice H5:1 Correo electrónico: marina.alarcon@ufrontera.cl 
Key words: adolescent development, juvenile delinquency, family relations, transgenerational patterns, family therapy (PsycInfo-APA).

\section{Significados do ato penal adolescente: perspectiva de suas mães}

- Resumo (analítico): com o objetivo de caracterizar os significados relativos ao ato criminoso que as mães de jovens infratores de leis de privação de liberdade têm em um Centro de Regime Fechado no Chile, foi realizada uma pesquisa qualitativa descritiva, utilizando uma amostra de casos críticos, com uma amostra de cinco participantes. A técnica de coleta de dados foi a entrevista semi-estruturada e a análise e interpretação dos dados obtidos foi realizada através da Análise Fenomenológica Interpretativa (IPA). Os resultados abordam cinco temas: Atribuição da origem da conduta criminal; Consequências da privação de liberdade; Fatores que ajudam os jovens a mudar seu comportamento; A revelação de atos criminosos e dinâmicas familiares. Foram discutidas as implicações para os processos de intervenção.

Palavras-chave: desenvolvimento de adolescentes, delinquência juvenil, relações familiares, padrões transgeneracional, terapia familia (PsycInfo-APA).

-1. Introducción. -1.1 Adolescencia y delincuencia. -1.2 relaciones familiares y adolescentes infractores. -2. Método. -2.1 Participantes. -2.2 Diseño. -2.3 Técnicas. -2.4 Procedimiento. -2.5 Plan de análisis. -2.6 Resguardos éticos. -3. Resultados. -4. Discusión. -Listado de referencias.

\section{Introducción}

La temática de la infracción de ley en la adolescencia es relevante en espacios políticos, públicos y privados, debiendo dirigirse la intervención a los ámbitos individuales, familiares y comunitarios. El objetivo general de las Orientaciones Técnicas del Servicio Nacional de Menores (Sename), entidad encargada de la labor en Chile, es «proporcionar una intervención multimodal en el marco de los Derechos del Niño que contribuya a reducir el riesgo de reincidencia, a través de la integración familiar y socio-comunitaria de los/as adolescentes condenados a régimen cerrado» (Sename, 2011, p. 6).

No obstante lo anterior y a más de 20 años de la firma de la Convención por los Derechos de la Infancia, realizar intervenciones integrales y diferenciales dirigidas hacia adolescentes infractores de ley y sus contextos de vida es aún una tarea pendiente (Erazo-Cortés, 2016).

Por esto, y a fin de contribuir a la optimización de las intervenciones a nivel familiar y comunitario que eviten la reincidencia, resulta interesante conocer las significaciones que poseen las familias respecto al actuar delictivo de sus hijos, específicamente a través de las miradas de las madres, pues son ellas las encargadas principales de la crianza y cuidados familiares en Latinoamérica y Chile (Espejo, Filgueira, \& Rico, 2010; Montecino, 2012; Valdés, 2007).

\subsection{Adolescencia y delincuencia}

La adolescencia es una «etapa de desarrollo efectivo y progresivo de la autonomía personal, social y jurídica» (Unicef, 2013, p. 9). Para la Organización Mundial de la Salud (OMS), «se propone que el término jóvenes se refiere, en general, al periodo global de 10 a 24 años de edad, observándose que en la práctica, los vocablos adolescentes, jóvenes y juventud son intercambiables») (OMS, 1986, p. 12).

Actualmente, ser adolescente en Chile implica fuertes exigencias, que se vivencian individualmente, relativas a responder a una sociedad neoliberal a fin de garantizar de alguna manera el tener a corto, mediano y largo plazo un bienestar económico que permita el desarrollo del individuo (Álvarez-Valdés \& Garcés-Sotomayor, 2017). Si bien en muchos casos este desafío implica la búsqueda 
de una mayor y mejor educación, en otros se configuran prácticas contraculturales asociadas a un aumento de la conflictividad y movilización social (Molina-Chávez \& Álvarez-Valdés, 2017), así como también a la infracción de la ley y a prácticas de delincuencia.

La definición de delincuencia hace referencia a la actividad que realiza toda persona que se aparta de la ley, es decir, que comete un acto ilícito (Fréchette \& LeBlanc, 1987), ya que es la ley el marco que regula las normas sociales y, por tanto, la que determina la delincuencia en cuanto a identificar formalmente los actos prohibidos y considerados como punibles, además de atribuir el estatus de delincuente a un individuo en particular.

Respecto a la delincuencia que se presenta en el período adolescente, investigaciones dan cuenta de dos grupos: la delincuencia común y la delincuencia distintiva. La primera hace referencia a los jóvenes que a lo largo del periodo adolescente pueden presentar conductas delictivas, pero estas cesarán al finalizar la adolescencia. La delincuencia común permitiría a los adolescentes comprobar los límites, no traspasarlos, y consolidar su orientación social (Fréchette \& LeBlanc, 1987; Laporte, 2009). En el segundo grupo, en cambio, se evidencia precocidad en el actuar delictivo, sostenido y diverso, resultando en la consolidación del sujeto en un modo de funcionamiento propiamente disocial, orientado al antagonismo y a la oposición de los valores sociales (Fréchette \& LeBlanc, 1987; Laporte, 2009).

Al respecto, como plantean Zambrano y Pérez-Luco (2004), cuando la infracción a la ley se presenta de manera persistente en muchos casos sería el resultado de desventajas sociales, desesperanza y dificultades para satisfacer necesidades.

En este sentido, se plantea la existencia de factores individuales y familiares, que mientras más estén presentes, mayor será el riesgo de desarrollar infracciones de ley persistentes. Entre los factores individuales se encuentran el temperamento difícil, el déficit de atención, la hiperactividad y la manifestación de conductas agresivas. En los factores familiares se encuentran la pobreza de la relación de apego con los padres, la supervisión parental débil, la disciplina inconsistente y el que uno o los dos padres posean problemas en salud mental o abuso de alcohol o drogas (Zambrano \& Dionne, 2009).

\subsection{Relaciones familiares y adolescentes infractores}

Se comprende como concepto de familia a «un grupo de personas, unidas emocionalmente o por lazos de sangre, que han vivido juntos el tiempo suficiente como para haber desarrollado patrones de interacción e historias que justifican y explican tales patrones» (Minuchin, Lee, \& Simon, 1998, p. 47). Se evidencia una multiplicidad de conformaciones familiares posibles, siendo sus tareas esenciales la individuación y, a su vez, el otorgar un sentimiento de pertenencia (Minuchin \& Fishman, 1983).

Así mismo, si pensamos en la familia como un sistema, ello «significa observarla a través de sus miembros, en las relaciones que estos miembros establecen entre sí, y las regularidades que aparecen en sus secuencias de comportamientos» (Bernales, 1985, p. 1).

Si bien las familias serían las encargadas de transmitir valores para lograr la adaptación a las normas sociales establecidas (Zambrano \& Pérez-Luco, 2004), no es lo único que transmitirían; es así como De la Aldea (2004) hace referencia a que en la familia existen repeticiones y, desde su experiencia clínica, se evidencian transmisiones familiares de patologías, soluciones e implicaciones.

En cuanto a la relación entre familia y adolescentes infractores de ley, se han visualizado dificultades estructurales y funcionales en las dinámicas familiares de adolescentes infractores de ley (Alboukordi, Nazarí, Nouri, \& Khodadadi, 2012; Farrington, Coid, \& Murray, 2009; Koudou, 1996; Rodríguez \& Torrente, 2003; Varela, 2011; Zambrano \& Pérez-Luco, 2004). En este sentido, Zamorano (2009) encontró que las familias de adolescentes infractores de ley eran en su mayoría familias reconstituidas con dificultades para desarrollar una nueva identidad familiar y donde coexistirían relaciones con una alta conflictividad y un bajo nivel de vínculos cercanos y confiables.

Respecto a los roles ejercidos dentro del sistema familiar, se ha observado una disminuida 
diferenciación entre los miembros y escasos recursos en los padres para establecer normas a sus hijos, por lo que estos no pondrían límites respecto a su actuar (Zamorano, 2009). Esto podría asociarse a que estas familias se caracterizarían por evitar abordar los conflictos, no aceptando críticas y presentando dificultades en cuanto a la comunicación de sus miembros, al igual que falta de apoyo, seguridad y afectividad (Amarís, Amar \& Jiménez, 2002). Blazei, Iacono y Krueger (2006) señalan la importancia de considerar la historia familiar, ya que se ha visto que existe mayor riesgo de infringir la ley si el adolescente tiene padres que también lo han hecho.

El resultado de la investigación realizada por Tolou-Shams, Hadley, Conrad y Brown (2012) considera entre los factores familiares relacionados con la delincuencia juvenil las malas relaciones familiares y conflictos conyugales, la falta de supervisión parental, las carencias educativas de los padres, las prácticas educativas parentales autoritarias y agresivas, las carencias afectivas, la delincuencia y privación de libertad de los padres (Farrington, 2001; Morales, 2002; Sanabria \& Uribe, 2010).

En cuanto a las figuras paternas de adolescentes infractores de ley, el estudio realizado por Amarís, Algarín, Beltrán y Cruz (2005) da cuenta que el padre se encontraría ausente y lejano, por lo que existe una sobrecarga de la figura materna, primando su presencia en un $85.7 \%$ de los casos estudiados. La madre, por tanto, es la que imparte la autoridad, toma las decisiones en el hogar, en lo educacional, en lo afectivo, en lo económico y en la crianza, estableciéndose en muchos casos una familia con la inclusión de un padrastro o simplemente una familia monoparental.

Asimismo, Silva y Martínez-Guzmán,(2017)observan que las metas, opciones y autorepresentación de los propios adolescentes formarán parte de diversas producciones culturales y contraculturales juveniles con las que buscarán insertarse en el mundo adulto y en las cuales la interacción con sus padres o familiares cercanos podrá moderar la influencia de factores de riesgo psicosocial, en la medida que impliquen apoyo, prácticas de retroalimentación y expectativas positivas y reales. Por lo que resulta de gran relevancia indagar desde dónde los padres y en especial las madres se plantearán estas eventuales interacciones.

A partir de lo expuesto, se considera relevante comprender ¿cuáles son los significados respecto del actuar delictivo que poseen las madres de adolescentes infractores de ley privados de libertad? Planteándose como objetivo general el caracterizar los significados respecto del actuar delictivo que poseen las madres de adolescentes infractores de ley privados de libertad en el Centro de Régimen Cerrado de la Región de Los Ríos, Valdivia, Chile; y como objetivos específicos: a) distinguir los factores que inciden en el inicio de la delincuencia desde la mirada de las madres de adolescentes privados de libertad; b) identificar las consecuencias que la privación de libertad de sus hijos ha traído a las madres; y c) describir la dinámica familiar presente en la familia nuclear de las madres entrevistadas, según el reporte que ellas entregan.

\section{Método}

\subsection{Participantes}

El muestro utilizado fue el de casos críticos, ya que se consideró relevante la experiencia que poseen las participantes respecto a su experiencia (Flick, 2004). El tamaño de la muestra fue de cinco participantes (tabla 1), apuntando la investigación a explorar en detalle las percepciones e interpretaciones de las madres respecto del fenómeno en estudio de manera detallada (Smith \& Osborn, 2009).

Los criterios de inclusión establecidos fueron: ser madres de adolescentes varones sancionados por la ley de Responsabilidad Penal Adolescente, que presentasen un comportamiento delictivo persistente y que se encuentrasen privados de libertad en el Centro de Régimen Cerrado de Valdivia. Los jóvenes habían sido condenados a régimen cerrado entre los 14 y 18 años de edad, sancionados por el delito de robo, siendo este el delito que más se registra en la población chilena. 
Se excluyeron de la muestra las madres que contaran con diagnóstico de psicosis o depresión actual o en remisión, debido a que los resultados podrían verse influidos por la sintomatología de aquellos estados.

\subsection{Diseño}

Se realizó una investigación cualitativa de tipo descriptivo, a fin de conocer los significados que las personas asignan a sus experiencias, tomando en cuenta el punto de vista de cada uno de los participantes, es decir, de su subjetividad (Hernández, Fernández, \& Baptista, 2010).

Tabla 1. Datos de la muestra

\begin{tabular}{ccccc}
\hline $\begin{array}{c}\text { Nombres } \\
\text { (han sido cambiados) }\end{array}$ & $\begin{array}{c}\text { Años condena } \\
\text { hijo }\end{array}$ & $\begin{array}{c}\text { Tiempo } \\
\text { cumplimiento } \\
\text { condena }\end{array}$ & $\begin{array}{c}\text { Edad } \\
\text { hijo }\end{array}$ & Estado civil \\
Alejandra & 3 & 8 meses & 16 años & Casada \\
Francisca & 10 & 2 años & 20 años & Casada \\
Mónica & 2 & 1 año & 18 años & Separada \\
Raquel & 1 & 8 meses & 18 años & Casada \\
Victoria & 3 & 8 meses & 17 años & Casada \\
\hline
\end{tabular}

\subsection{Técnicas}

Se realizó una entrevista individual semi-estructurada a cada participante, utilizando una pauta de entrevista que guió las preguntas realizadas, pudiendo a su vez incorporar preguntas que se visualizaran pertinentes al momento de la entrevista (Hernández et al., 2010). Cada entrevista tuvo una duración aproximada de una a dos horas.

Así mismo, se utilizaron notas de campo para registrar reflexiones e ideas importantes que surgieron al momento de la entrevista (Flick, 2004).

\subsection{Procedimiento}

El acceso a la muestra se desarrolló a partir del juicio profesional de los encargados de caso de los adolescentes privados de libertad que cumplieron con los criterios de inclusión. Para ello se sostuvo una entrevista con los encargados de caso quienes, al tener relación directa con la familia de los jóvenes, les consultaron a las madres su disposición voluntaria, con carácter confidencial, de ser parte de esta investigación. Una vez las madres aceptaron, se realizó el primer contacto, en donde se les hizo entrega y se les explicó lo mencionado en el consentimiento informado para que lo firmaran si estaban de acuerdo con lo expuesto.

Debido a que se entrevistó a madres de jóvenes que cumplen condena en el Centro de Régimen Cerrado de Valdivia, perteneciente al Servicio Nacional de Menores, se envió una carta al Director Regional de Sename de la región de Los Ríos para que autorizara esta investigación.

La entrevista fue grabada completamente y luego se transcribió la información verbal y paraverbal, como pausas en el discurso, elevaciones de voz y entonación.

\subsection{Plan de análisis}

El proceso de análisis e interpretación de la información se realizó a partir de los datos encontrados, realizándose triangulación por investigador y experto de área de la psicología durante todo el proceso de investigación (Stake, 2007). 
Se realizó un análisis de contenido convencional, que consideró una lectura completa de las entrevistas realizadas, un proceso de codificación que posteriormente fue clasificado en categorías, las que fueron agrupadas en núcleos de significado para posteriormente ser organizadas en un diagrama que permitió explicar y dar cuenta del fenómeno (Hsieh \& Shannon, 2005). Se utilizó como criterio la saturación de contenido, la que se alcanza cuando hay redundancia en la información (Castillo \& Vásquez, 2003).

El enfoque elegido para analizar la información obtenida fue el análisis fenomenológico interpretativo (IPA), que se consideró como el más apropiado para un estudio de carácter cualitativo, al entregar la perspectiva de los participantes en cuanto a su experiencia y subjetividad respecto al fenómeno que se estudió (Lyons \& Coyle, 2007). De modo que las personas entrevistadas hablan de lo que piensan junto con lo que sienten, y el investigador debe interpretar el estado emocional y mental de lo que están diciendo (Smith \& Osborn, 2009).

Finalmente el análisis fue desarrollado de una manera narrativa, utilizando algunos datos o citas textuales para ejemplificar los hallazgos (Lyons \& Coyle, 2007).

\subsection{Resguardos éticos}

Previo a la realización de las entrevistas, a cada una de las participantes se les hizo entrega de un consentimiento informado que describía la finalidad de la investigación, la voluntariedad de su participación, la confidencialidad de los nombres, así como tener durante toda la investigación la posibilidad de retirarse sin que ello afectara el proceso de sus hijos. Además, se les informó del tiempo requerido de participación, la no retribución por participación, los riesgos y beneficios.

Para resguardar la confidencialidad de las participantes se cambiaron los nombres de estas en la transcripción, al igual que nombres de familiares y lugares geográficos a los que pudiesen referirse en la entrevista.

\section{Resultados}

Los principales resultados corresponden a cinco temas principales: a) origen de la conducta delictiva; b) consecuencias de la privación de libertad; c) factores que ayudan a que los jóvenes cambien su conducta; d) revelación del actuar delictivo; y e) dinámica familiar. Cada uno de ellos se divide en diversos subtemas, que otorgan una explicación más profunda del fenómeno en estudio (ver figura 1). 
Figura 1. Significados del actuar delictivo adolescente según sus madres

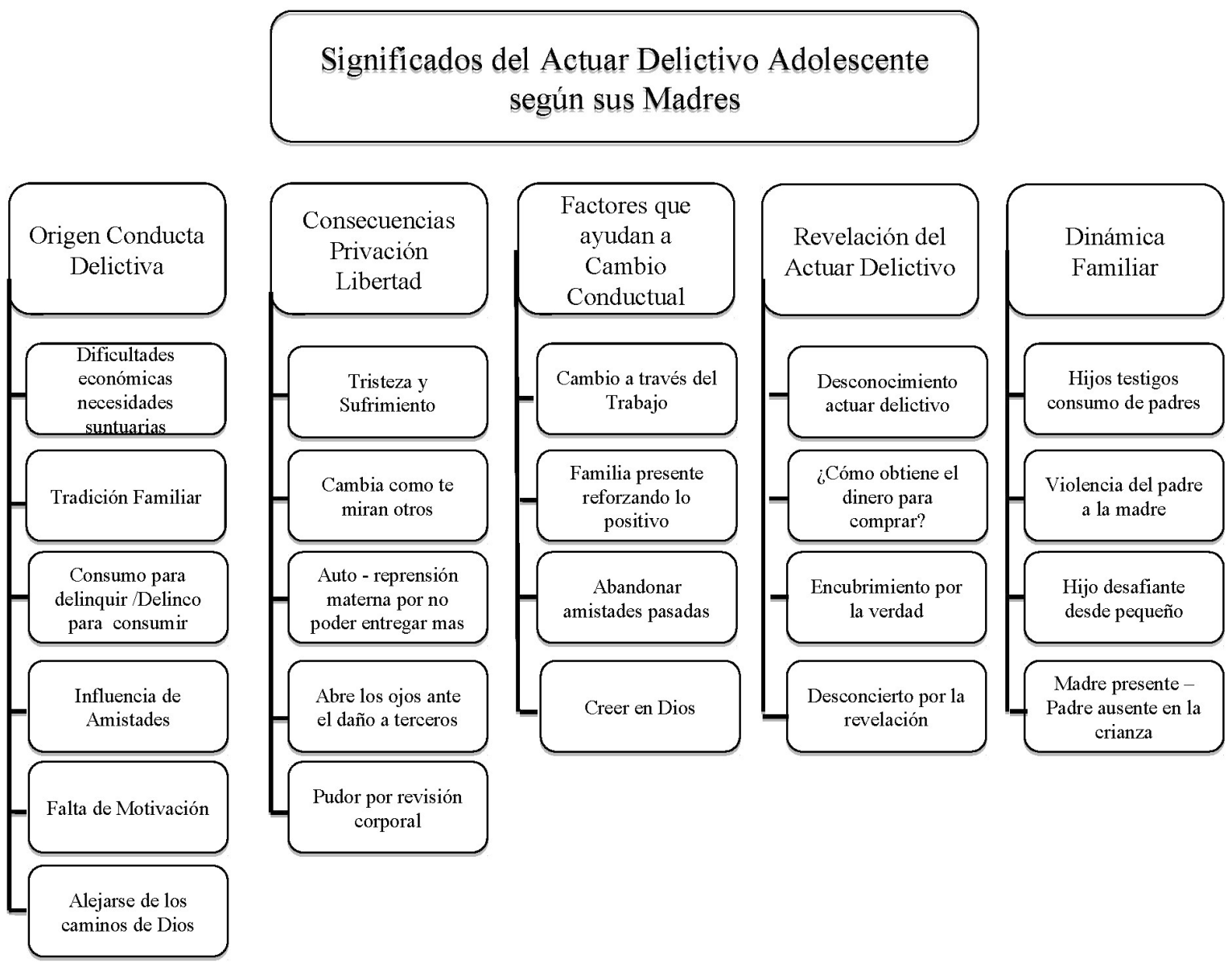

Respecto de la atribución del origen de la conducta delictiva, se encontraron, desde la perspectiva de las madres, seis modos de comprender el inicio del actuar delictivo de sus hijos:

a) Dificultades económicas para cubrir las necesidades suntuarias: cuatro de las madres consideraron que un motivador para que sus hijos cometieran delitos tenía relación con las dificultades económicas en el hogar para cubrir las necesidades suntuarias que sus hijos deseaban poseer. Mónica menciona: «Mi hijo lo hacía porque yo o mi ex marido no teníamos pa comprarle un par de zapatillas, o no teníamos pa comprarle un buzo que él quería, por eso lo hacía».

b) La delincuencia puede ser un ejemplo, una tradición familiar: relación con las acciones que tienen o tuvieron sus familiares más cercanos. Es importante mencionar que ninguna de las madres refirió tener o haber tenido conductas delictivas, pero sí sus maridos (o ex maridos), hermanos/as, tíos/as o primos/as del joven. Alejandra lo ilustra de la siguiente manera: «Mi marido años atrás anduvo robando, ¡años!, ¡años! Él anduvo robando, a la edad de mi hijo. Y yo creo que esto algún día, parece que fuera una herencia, una tradición, porque, ¿cómo los chicos salieron así?, porque yo digo, ¿cómo iban a salir así?»

c) Consumo para delinquir y delinco para consumir: considera que el consumo de sustancias, ya sea alcohol u otras drogas, tiene una relación de ida y vuelta respecto al delito: se consume para así poder delinquir, pero también se delinque para así tener dinero para comprar drogas o alcohol. Respecto a lo anterior, Francisca señala: «Yo pienso que mi hijo lo hacía, no sé, cuando se curaba hacía eso, cuando estaba sano nunca hacía eso (...) Ahí le daba la cuestión de ir a robar, pero cuando andaba sano no hacía esas cosas». Por otro lado, Alejandra señala: «Teniendo un plato de comida está 
todo bien, pero ellos querían plata, plata. Y muchas veces, como le diga, la plata es pa fumar no más, pa fumar esas cuestiones de pitos».

d) Inicio de la conducta delictiva influenciada por las amistades: Vivir en un contexto de mayor riesgo en cuanto a tener y contactarse con vecinos que infringen la ley de manera constante. Francisca señala: «Yo pienso que es por las amistades que tienen, porque hay otros niños que roban y se juntan con ellos y hacen lo mismo».

e) La falta de motivación se relaciona con el delinquir: Victoria consideró que la falta de motivación de los jóvenes tiene relación con el inicio de la delincuencia y lo expresó de la siguiente manera: «No hay ninguna cosa en los jóvenes hoy en día; no hay nada que los motive (...). La juventud se está perdiendo demasiado, porque no hay otras cosas nuevas para ellos. Ya el colegio les aburre, ya no tienen ganas de ir a estudiar»».

f) Alejarse de los caminos de Dios: el origen de la conducta delictiva se atribuye a alejarse de Dios. Lo expuesto se encontró en la narración de Alejandra, madre de dos hijos privados de libertad, convertida al cristianismo evangélico: «Yo pienso que es culpa mía, ese periodo de no haber ido a la iglesia. Señor es culpa mía que mis hijitos estén presos, porque yo, otra buena madre, otra no hubiera salido así»».

Respecto de las consecuencias que la privación de libertad de los hijos ha traído para madres, se observan cinco categorías que engloban consecuencias emocionales-internas o contextuales-sociales:

a) Tener un hijo preso conlleva tristeza y sufrimiento: se observa en cuatro de las cinco entrevistas y de manera reiterativa a lo largo de cada relato. Al preguntarle a Francisca cuáles eran sus sentimientos al saber que su hijo fue condenado a 10 años de privación de libertad, lo expresa de la siguiente manera: «Dolor, pena, pena para mí; no comía de repente; lloraba todo el día, mi marido igual».

b) Cambia el cómo te miran los otros si tus hijos delinquen: en tres de las cinco entrevistas realizadas y se daba tanto dentro de la familia, como con conocidos, vecinos y miembros de la iglesia en que se participaba. El ejemplo de Alejandra puede ayudar a comprender: «A mí a veces me critican, me dicen, usted hermana sus dos hijos delincuentes, y aquí y acá, y uno se siente mal cuando le dicen esas cosas».

c) Autorreprensión materna por no poder entregar más: tres de las cinco madres entrevistadas se responsabilizan por no haber podido hacer algo distinto frente al actuar delictivo de sus hijos, como haber frenado las conductas delictivas de sus hijos o haberles dado un mejor ejemplo, así como haber tenido mayores recursos para la familia. Este sentimiento pareciera estar cargado de culpa y tristeza, arraigado en lo profundo. Referente a esto, Raquel señala: «Si po'uno como madre creo que fallé; po'yo digo, estoy fallando yo, porque pa mejor no. Ahí me dije: a lo mejor no estudié, no soy una profesora, no tengo tanta plata hijo, no te puedo dar lo que tú queríai».

d) Vivir esta situación te abre los ojos para ver el daño hacia terceros: a partir del proceso que han vivido sus hijos, como la asistencia a tribunales, los juicios, testigos, etc., dos de las entrevistadas señalan que han podido ver el impacto de las conductas delictivas de sus hijos en otras personas. Esto se ejemplifica a través del relato de Alejandra: «Antes de vivir esta situación, decía los jueces son malos, condenan a los chicos, tantas condenas que les mandan (...). Pero uno no veía las consecuencias que estos chicos, hacían daño dentro de las casas, se metían a las casas a robar las cosas, capaz que igual de repente podían golpear, matar a alguien por robar algo».

e) Pudor por la revisión corporal: Raquel y Mónica hacen mención a la experiencia, nueva para ellas, de pasar por la revisión corporal de los funcionarios de Gendarmería para poder así visitar a sus hijos. Mónica refiere: «Te suben el sostén pa arriba, te bajan el calzón (...). De primera yo no estaba acostumbrada a que me revisen, si yo jamás había pisado ni siquiera la cárcel de adultos».

En relación a los factores que ayudan a que los jóvenes cambien la conducta delictiva, las madres hacen referencia a cuatro grandes aspectos: trabajo, familia, amistades y Dios:

a) El cambio a través del trabajo: se refiere a la creencia que una vez cumplida la condena en privación de libertad, la manera de no continuar delinquiendo debe ser al acceder al mundo laboral para así obtener dinero. Alejandra lo relata de la siguiente manera: «El día que mi hijo salga, yo lo 
voy a llevar a trabajar, ahora sí que me lo llevo a trabajar, porque después ya va a estar más maduro. Ya tiene que estar maduro para que el día que salga de aquí vaya a trabajar y gane su plata».

b) La familia debe estar presente, reforzando lo positivo: hace referencia a que la motivación de la familia para con su hijo sería relevante para generar o potenciar el cambio. Victoria señala: «La familia tendría que ser un apoyo de estar siempre ahí, no sé, tú vas a poder, lo vas a poder lograr».

c) Abandonar las amistades pasadas: aunque solo se menciona en un relato, se aprecia que en todas las entrevistas se visualizó que las relaciones de amistad de sus hijos influyeron en que ellos comenzaran a delinquir. Raquel dice: «Creo que pensando bien las cosas no más, dejando las amistades, porque mi hijo tiene muchos amigos; pero aquí, ¿dónde están los amigos?, los que iban a la casa, los que dormían de repente, los que comían en su mesa».

d) La necesidad de creer en Dios: hace referencia a que sería solo Dios el que lograría sanar y cambiar a las personas, sin este apoyo no lo lograrían. Mencionado por dos de las madres, siendo las mismas que hacen referencia a Dios en el tema de atribución del origen de la conducta delictiva. Victoria lo señala de la siguiente forma: «Mi hijo necesita hablar con Dios, que es el único Dios que es fiel y puede ayudarnos y sacarnos de todas esas cosas, de todas las heridas de nuestro corazón, de todas esas cosas que uno no pueda».

Referente al proceso de revelación del actuar delictivo, las madres plantean cómo con el paso del tiempo, y ya en la adolescencia de sus hijos, se fueron enterando, poco a poco, que estos delinquían. Lo anterior formaría parte de un proceso: van abriendo los ojos paulatinamente a partir de dudas y secretos, pasando por el no querer, a darse cuenta y, finalmente, concluir con la revelación; estar sería aconpañada de una sensación de estupefacción vivida por la madre hacia el actuar de su hijo. Al respecto se mencionan cuatro momentos:

a) El desconocimiento del actuar delictivo del hijo: se refiere a que las madres desconocían la actividad delictiva de sus hijos, sin sospechar de conductas extrañas o diferentes al interior del hogar. Se hace hincapié en que los robos fueron realizados en el exterior del sistema familiar. Respecto a esto Raquel refiere: «Entonces, cuando dijeron eso, que mi hijo lo hacía por fuera, sin que yo supiera, porque en la casa no lo hacía; entonces mi hijo hacía todo eso que hizo de la delincuencia lo hizo por fuera, yo no me di cuenta».

b) ¿Cómo obtiene el dinero para comprar?: da cuenta de la interrogante materna frente a ver a su hijo con prendas de ropa de alto valor económico o darse cuenta que mantiene altas sumas de dinero en su poder, sin que ella o algún familiar se lo entregara y sin que el hijo tuviera otra vía de ingreso, como por ejemplo un trabajo. Es también Raquel quien indica respecto a su historia: «Una vez lo vi con unas zapatillas, y le dije: ¿de dónde salieron esas zapatillas? No, me dijo, me las regalaron. Esas no te las regalaron, dije ¿quién te las regaló? No, sí me las regalaron. Y eran unas zapatillas buenas, pongámosle que esas zapatillas estaban entre 70 y 80 lucas, porque yo las vi, cuando fui al centro las vi, y yo dije: cómo, quién le iba a regalar un par de zapatillas con ese precio; ni a sus abuelos ni a sus tíos les alcanza».

c) Encubrimiento de la verdad: se relaciona en algunos casos con el silencio y en otros con las versiones alternativas que el hijo da a su madre respecto a la obtención de bienes o dinero. Alejandra expone su vivencia así: «Andas leseando afuera, a mí se me hace que andai en cosas raras. No, si no mami - decía él — mis tíos me prestan plata, mis tíos. Y se sacaba la plata por ahí. A mí me mentía».

d) Desconcierto por la revelación: da cuenta del asombro y la incomprensión de las madres respecto a las motivaciones del actuar delictivo su hijo. Raquel da cuenta de su experiencia de la siguiente manera: "Yo llegaba del trabajo y veía que mis dos hijos estaban durmiendo, no había ningún problema, ningún rollo, entonces es inexplicable en qué momento se metió en eso, porque también él tenía de todo: tenía computador, tenía... no le faltaba nada en la casa. Tenía comida, su papá lo adora, yo también, su familia, sus tíos, su abuela que lo adora que... y por eso no entiendo qué pasó, por qué se produjo esto».

Finalmente, respecto de la dinámica familiar, se observa cómo las madres experimentan sus relaciones familiares, específicamente con sus hijos y con sus maridos. Además, se da cuenta de las 
relaciones conyugales y parentales, así como de actividades propias de las madres que ellas consideran que influyen en la vida y el actuar de sus hijos.

Esta temática apareció espontáneamente en el discurso de las madres, sin necesidad de preguntar, relacionando su dinámica familiar con el actuar delictivo de sus hijos, sintiendo que de alguna manera la primera habría influido en la segunda.

Por otra parte, las madres entrevistadas dan cuenta, con un tono de pesar y rabia, de cómo han sido responsabilizadas por sus maridos respecto a la privación de libertad de sus hijos, a pesar de estar presentes en la crianza y sus esposos ausentes en esta labor.

Al respecto se observan cuatro categorías:

a) Hijos testigos del consumo de los padres: da cuenta del consumo de drogas o alcohol, de uno o ambos padres, estando sus hijos presentes. Francisca cuenta su experiencia: «Mi marido toma, y yo antes que tuviera a mi hija también tomaba. Mi hijo lo veía, lo veía mi otro hijo también, todos lo veían. Me gustaba tomar».

b) Violencia del padre a la madre observada por los hijos: se encontró en el relato de cuatro de las cinco madres entrevistadas. La emergencia de esta temática estuvo acompañada de un tinte de pudor y silencio. Raquel lo refiere de la siguiente forma: «Mi hijo cuando ya fue grande se dio cuenta que sí, que el papá, que el papá me había pegado, porque una vez vio que me dio un combo».

c) Hijo con actitud desafiante desde pequeño: hace referencia al periodo comprendido entre los cuatro y siete años de edad, dependiendo de cada caso, donde los hijos iniciaron conductas desafiantes y agresivas con otros niños. Raquel dice: «Mi hijo cuando era chico era peleador, le gustaba pelear, pegarle a los cauros más chicos que él».

d) En la crianza la madre está presente, el padre ausente: a lo largo del desarrollo de los hijos, ha sido la madre la que se encuentra mayoritariamente presente en el cuidado, enseñanza y crianza de los hijos, ya que el padre se ha ausentado por motivos laborales fuera de la ciudad de residencia de la familia o saliendo muy temprano en la mañana y regresando a altas horas de la noche, por lo que el quehacer diario respecto a la crianza de los hijos recaía en la madre. Cuando el padre se encontraba en el hogar los fines de semana, se dedicaba a jugar o complacer a los hijos, sin establecer normas o límites. Al respecto, Raquel refiere: «Mi marido trabaja en L.; siempre trabajó afuera, o sea, no puedo decir que no era su papá tampoco, porque él le dio todo a su hijo, pero lamentablemente no le podía dar más tiempo con él, porque tenía que trabajar (...). Yo fui mamá y papá para ellos».

\section{Discusión}

La temática en estudio fue descrita desde la vivencia subjetiva de cada una de las cinco participantes quienes conforman familias nucleares biparentales y una familia nuclear monoparental con jefatura de hogar femenina. Lo anterior coincidiría parcialmente con el estudio de Zamorano (2009), pues si bien no se observaron familias reconstituidas, se observan problemáticas en las dinámicas familiares que pudieran vincularse con dificultades al momento de visualizar y atender necesidades de cuidado o supervisión para con sus hijos. Estas dificultades relacionales, desde la mirada de la terapia familiar, se consideran un importante foco de intervención a considerar, siendo necesario diferenciar entre la estructura familiar y los procesos relacionales que implica la cotidianeidad a la que están expuestos los miembros de cada familia. Dicho abordaje sin dudas implica cuestionar los imaginarios de los interventores respecto a lo que se considera saludable en el «hacer familia» pues, como señalan Valdenegro y Calderón-Flández (2016), las prácticas discursivas desarrolladas por los interventores presentan un carácter subjetivador y no se circunscriben a los límites programáticos, respondiendo los sujetos a posiciones sociales; por lo que en muchas ocasiones se ha intervenido con las familias desde lo que se ha considerado como la estructura socialmente esperada, dejando de lado los procesos relacionales que afectan el bienestar de sus miembros y, en especial, el de niñas, niños y adolescentes.

En este sentido, uno de los criterios de inclusión de la muestra correspondía a que los hijos correspondieran al grupo de delincuencia persistente, en el cual Laporte (2009) menciona la 
disminuida supervisión parental, encontrándose que en todos los casos existía un desconocimiento o conocimiento parcial por parte de las madres respecto al actuar delictivo de sus hijos, lo que hace pensar en la existencia de una baja supervisión parental.

Resulta relevante destacar que una de las atribuciones otorgadas por las madres respecto al origen de la conducta delictiva tiene relación con la dificultad económica de los padres para adquirir bienes suntuarios que son deseados por sus hijos; ello coincide con lo expuesto por Zambrano y Pérez-Luco, (2004) referente a que la infracción de ley se relaciona con dificultades para resolver necesidades básicas y materiales. Estos bienes suntuarios, como ropa o accesorios de marca, no corresponderían a una necesidad básica (sí material), lo que confirmaría la motivación actual de la juventud chilena por tener acceso a un conjunto de servicios y bienes de consumo que el mercado promueve (DuarteQuapper, Aniñir-Manríquez, \& Garcés-Sotomayor, 2017). Lo anterior conlleva implicaciones para procesos de intervención donde parece necesario cuestionar tanto los valores y necesidades que los medios de comunicación promueven, como la mirada respecto de la cual la infancia y adolescencia que transita por los tribunales sean los denominados por Andrés-Candelas (2016) «sujetos peligrosos», que deban ser necesariamente separados del resto de la sociedad.

Por otra parte, las madres creen que otro de los orígenes del comportamiento delictivo correspondería a una tradición familiar, debido a que los padres o familiares directos tienen o tuvieron problemas con la justicia. Lo anterior puede ser visto como un factor de riesgo o predisponente para la comisión de ilícitos pues, como señala Zambrano y Pérez-Luco (2004), la familia sería la encargada de transmitir los valores para lograr la adaptación al sistema social. Los resultados antes mencionados coincidirían con lo expuesto por Blazei, Iacono y Krueger (2006), Farrington, Coid y Murray, (2009) y Alboukordi et al. (2012) respecto a que existiría un mayor riesgo de infringir la ley si el adolescente tiene padres que también lo han hecho.

En cuanto a la influencia de las amistades en el inicio del actuar delictivo y la relación entre consumo de sustancias y delincuencia, las madres consideraron a ambos como factores relevantes, lo que coincide con lo descrito por Andrews y Bonta (2007) respecto a que se consideran situaciones de alto riesgo predisponentes al actuar delictivo.

En relación a las concepciones que poseen las madres respecto a cómo sus hijos pueden realizar un cambio de vida, uno de los resultados refiere que la familia debe estar presente a través del refuerzo y motivación, lo que coincide con lo expuesto por Minuchin y Fishman (1983) y por Andrews y Bonta (2007) respecto a la importancia de la familia en cuanto a estar presente en la crianza de los hijos, siendo parte del rol parental y de las tareas a desarrollar por este.

Así mismo, la relación que las madres mencionan entre la infracción de ley de sus hijos y el haber sido testigos de la violencia ejercida por el padre hacia la ellas, es coincidente con lo expuesto por Farrington (2001), Morales (2002) y Sanabria y Uribe (2010), para quienes este tipo de conflicto conyugal se relacionaría con la delincuencia juvenil.

Por otro lado, se rescata la vivencia de las madres entrevistadas donde refieren que han estado presentes en el hogar para cuidar, contener e intentar normar a sus hijos, además de aportar económicamente a través de su trabajo fuera del hogar. Los padres de los adolescentes estarían ausentes de la crianza y cuidados de los hijos, siendo los proveedores principales del hogar. Estos hallazgos coinciden con lo expuesto por Sunkel (2006) y Espejo, Filgueira y Rico (2010), en cuanto a que, si bien en las familias latinoamericanas ha existido un aumento del ingreso de la mujer al mercado laboral, ello no ha implicado equiparar responsabilidades respecto de la crianza de los hijos.

Los resultados de esta investigación permiten concluir que las madres entrevistadas otorgan múltiples significados y causas al actuar delictivo de sus hijos, en donde emergen fuertes y diversos sentimientos y emociones ligados a este proceso que iniciaría con la develación del actuar delictivo de su hijo, para con el tiempo transitar por la experiencia de tener a su hijo privado de libertad. Al respecto se considera relevante desarrollar intervenciones reeducativas pedagógicas y terapéuticas, que incorporen a los miembros de la familia en procesos de resignificación ante la infracción a la ley de los adolescentes (Ávila-Navarrete, 2017); así como también intervenciones familiares-sistémicas 
que permitan trabajar con jóvenes privados de libertad y sus familias una vez egresados, a fin de propiciar cambios permanentes en las dinámicas familiares.

Lo anterior, implica establecer procesos de seguimiento y acompañamiento, posiblemente más allá de los mandatos judiciales establecidos, lo que conlleva el favorecer la gestión de las redes sociales donde confluyan actores públicos y privados que faciliten la reinserción social de los sujetos adolescentes infractores, como plantean Andrade-Gyllen, García-Ojeda y Zambrano-Constanzo (2016); así, generar espacios para la reflexión y potenciación del trabajo en redes sociales, que permitan rescatar el conocimiento de cada actor para lograr los objetivos de la ley de responsabilidad penal adolescente.

Dentro de las limitaciones de este estudio es necesario mencionar el tamaño y lugar de la muestra, en tanto que las cinco participantes correspondían a madres de jóvenes infractores de ley del mismo Centro.

Como sugerencias para futuras investigaciones se considera relevante indagar en familias con hijos infractores de ley donde la crianza sea ejercida activamente por ambos padres, así como indagar respecto de las dinámicas familiares en personas que, habiendo delinquido en la adolescencia, no han continuado haciéndolo en la adultez, observando cómo han intervenido actores de distintos ámbitos sociales, de salud o de educación.

\section{Listado de referencias}

Alboukordi, S., Nazari, A., Nouri, R., \& Khodadadi, J. (2012). Predictive factors for juvenile delinquency: The role of family structure, parental monitoring and delinquent peers. International Journal of Criminology and Sociological Theory, 5(1), 770-777.

Álvarez-Valdés, C., \& Garcés-Sotomayor, A. (2017). La construcción de generación en los discursos juveniles del Chile actual. Revista Latinoamericana de Ciencias Sociales, Niñez y Juventud, 15(2), 991-1004. doi:10.11600/1692715x.1521303102016

Amarís, M., Algarín, M., Beltrán, O., \& Cruz, J. (2002). Dinámica de las familias de menores infractores en la ciudad de Barranquilla. Barranquilla: Uninorte.

Amarís, M., Amar, J., \& Jiménez, M. (2005). Dinámica de las familias de menores con problemas psicosociales: el caso del menor infractor y la menor explotada sexualmente. Revista Latinoamericana de Ciencias Sociales, Niñez y Juventud, 3(2), 141-174.

Andrade-Gyllen, C., García-Ojeda, M., \& Zambrano-Constanzo, A. (2016). Modelo operativo de gestión de redes sociales para el sistema penal adolescente, Chile. Revista Latinoamericana de Ciencias Sociales, Niñez y Juventud, 14(1), 247-260. doi: 10.11600/1692715x.14116101214

Andrés-Candelas, M. (2016). La construcción socio-histórica de la «infancia peligrosa» en España. Revista Latinoamericana de Ciencias Sociales, Niñez y Juventud, 14(1), 95-106. doi:10.11600/ $1692715 x .1415220615$

Andrews, D., \& Bonta, J. (2007). Risk-need-responsivity model for offender assessment and rehabilitation. Recuperado de:

http://publications.gc.ca/site/eng/317814/publication.html

Ávila-Navarrete, V. C. (2017). ¿Corresponsabilidad familiar en instituciones de reeducación para adolescentes infractores? Revista Latinoamericana de Ciencias Sociales, Niñez y Juventud, 15(2), 1191-1206. doi:10.11600/1692715x.1522712102016

Bernales, S. (1985). Individuo y familia: una visión sistémica. Recuperado de: http://www.unida. org.ar/Bibliografia/documentos/Desarrollo_Sustentable/Economia_y_Ecologia/Individuo_y_ Familia_Sergio_Bernales_EE_4_o_5.doc

Blazei, R., Iacono, W., \& Krueger, F. (2006). Intergenerational transmission of antisocial behavior: How do kids become antisocial adults? Applied and Preventive Psychology, 11, 230-253. 
Castillo, E., \& Vásquez, M. (2003). El rigor metodológico en la investigación cualitativa. Colombia Médica, 34(3), 164-167.

De la Aldea, E. (2004). Lo transgeneracional y lo multicultural en las intervenciones con familias. Ponencia presentada en XIX Jornadas de AEN Salud Mental, Diversidad y Cultura. Nuevos Retos en las Fronteras del Saber y la Atención, Barcelona, España.

Duarte-Quapper, K., Aniñir-Manríquez, D., \& Garcés-Sotomayor, A. (2017). De encuentros y desencuentros entre jóvenes y personas adultas a propósito de salir de la enseñanza secundaria en Chile. Revista Latinoamericana de Ciencias Sociales, Niñez y Juventud, 15(1), 373-388. doi: 10.11600/1692715x.1512307032016

Erazo-Cortés, M. (2016). Reflexiones sobre la política pública dirigida a jóvenes en conflicto con la ley penal, residentes en instituciones cerradas de Colombia. Revista Iberoamericana de Psicología: Ciencia y Tecnología, 9(2), 87-94.

Espejo, A., Filgueira, F., \& Rico, M. (2010). Familias latinoamericanas: organización del trabajo no remunerado y de cuidado. México, D. F.: Cepal. Recuperado de: http://www.cepal.org/ publicaciones/xml/2/41822/dp-familias-cuidado.pdf

Farrington, D. (2001). Key results from the first forty years of the Cambridge study in delinquent development. En T. Thornberry, \& M. Krohn (Eds.), Taking stock of delinquency: An overview from contemporary longitudinal studies (137-183). Nueva York: Kluwer/Plenum.

Farrington, D., Coid, J., \& Murray, J. (2009). Family factors in the intergenerational transmission of offending. Criminal Behavoir and Mental Health, 19, 109-124. doi:10.1002/cbm

Flick, U. (2004). Introducción a la investigación cualitativa. Madrid: Morata.

Fréchette, M., \& LeBlanc, M. (1987). Délinquances et délinquants. Québec: Gaëtan Morin Éditeur.

Hernández, R., Fernández, C., \& Baptista, P. (2010). Metodología de la investigación. Lima: Mc Graw Hill.

Hsieh, H., \& Shannon, S. (2005). Three approaches to qualitative content analysis. Qualitative Health Research, 15, 1277-1288.

Koudou, O. (1996). Intolérance sociale, continuation du comportement delinquent chez l'adolescente et stratégie preventive. Déviance et Société, 20(2), 141-151. doi:10.3406/ds.1996.1601

Laporte, M. (2009). Modelo integrado de intervenção diferencial. Québec: Centre de Jeunesse de Montérégie.

Lyons, E., \& Coyle, A. (2007). Analysing qualitative data in psychology. Londres: Sage.

Minuchin, S., \& Fishman, Ch. (1983). Técnicas de terapia familiar. Barcelona: Paidós.

Minuchin, S., Lee, W., \& Simon, G. (1998). El arte de la terapia familiar. Barcelona: Paidós.

Molina-Chávez, W. M., \& Álvarez-Valdés, C. (2017). Imaginarios sociales sobre lo juvenil en el Chile contemporáneo. Revista Latinoamericana de Ciencias Sociales, Niñez y Juventud, 15(1), 85-100. doi:10.11600/1692715x.1510407032016

Montecino, S. (2012). Madres y huachos: alegorías del mestizaje chileno. Santiago de Chile: Catalonia.

Morales, H. (2002). La familia: ¿un agente criminógeno? Revista de Investigación Bolivariana, 5, 2-15.

OMS. (1986). Young people's health: A challenge for society (Technical report series 731.1986). Recuperado de: https://extranet.who.int/iris/restricted/handle/10665/41720?mode=full

Rodríguez, A., \& Torrente, G. (2003). Interacción familiar y conducta antisocial. Boletín de Psicología, 78, 7-19.

Sanabria, A., \& Uribe, A. (2010). Factores psicosociales de riesgo asociados a conductas problemáticas en jóvenes infractores y no infractores. Perspectiva Psicológica, 6, 257- 274.

Sename. (2011). Orientaciones técnicas de centros de régimen cerrado. Santiago de Chile: Ministerio de Justicia 
Silva, C., \& Martínez-Guzmán, M. L. (2017). El self adolescente desde la perspectiva contextual: pobreza, viviendas sociales, apoyo parental y participación. Revista Latinoamericana de Ciencias Sociales, Niñez y Juventud, 15(1), 117-130. doi:10.11600/1692715x.1510605022016

Smith, J., \& Osborn, M. (2009). Interpretative phenomenological analysis. En J. Smith (Ed.), Qualitative psychology: A practical guide to research methods (pp. 1-288). Londres: Sage.

Stake, R. (2007). Investigación con estudio de casos. Madrid: Morata.

Sunkel, G. (2006). El papel de la familia en la protección social en América Latina. Serie Políticas Sociales Cepal, 120, 1-66.

Tolou-Shams, M., Hadley, W., Conrad, S., \& Brown, L. (2012). The role of family affect in juvenile drug court offenders' substance use and HIV risk. Journal of Child and Families Studies, 21, 449-456. doi:10.1007/s10826-011-9498-4

Unicef. (2013). Superando el adultocentrismo. Santiago de Chile: Unicef.

Valdenegro, B., \& Calderón-Flández, C. (2016). Alteridad, infancia y delincuencia: análisis discursivo desde programas sociales hacia infancias en Chile. Revista Latinoamericana de Ciencias Sociales, Niñez y Juventud, 14(2), 1191-1204. doi:10.11600/1692715x.1422107071

Valdés, X. (2007). Notas sobre la metamorfosis de la familia en Chile. Santiago de Chile: Comisión Económica para América Latina y el Caribe (Cepal).

Varela, J. (2011). Juventud, violencia y delincuencia desde una mirada de la prevención social del delito. Revista Observatorio Juventud, 29, 39-48.

Zambrano, A., \& Dionne, J. (2009). Intervención con adolescentes infractores de ley. El Observador, $5,34-56$.

Zambrano, A., \& Pérez-Luco, R. (2004). Construcción de identidad en jóvenes infractores de ley: una mirada desde la psicología cultural. Revista de Psicología de la Universidad de Chile, 13, $115-132$.

Zamorano, E. (2009). Articulación de miradas para una aproximación a la inclusión social de adolescentes infractores de ley: teorías de redes sociales y de sistemas sociales. Revista Mad. Revista del Magíster en Análisis Sistémico Aplicado a la Sociedad, 21, 45-64. 